\title{
Basic Properties of Tapes Containing Variable Amounts of Special Additive for Maintenance of Whiteness
}

\author{
Donatas Petrulis $^{a *}$, Artūras Petravičius ${ }^{a, b}$, Salvinija Petrulyte ${ }^{a}$ \\ ${ }^{a}$ Department of Materials Engineering, Faculty of Mechanical Engineering and Design, Kaunas \\ University of Technology, Kaunas, Lithuania \\ ${ }^{b}$ KLAMETA Co., Kaunas, Lithuania
}

Received: September 2, 2015; Revised: April 19, 2016; Accepted: June 3, 2016

\begin{abstract}
The present paper studies the effects of the additions between 3.00 and $7.00 \mathrm{wt} \%$ of additive Granic 422 instead of polypropylene on polymeric tapes properties as color difference, structure and tensile parameters. Micro-structural analysis revealed additional agglomerations of calcium carbonate particles on the surfaces of the tapes after application of new portions of the variable additive. Compositionproperty relations showing the changes in properties of tapes were suggested. For increase in color difference of the tapes from zero to 0.18 , a logarithmic relation was used. For other indices, the linear relations were proposed. On the basis of the relations, the positive changes of $2.0-2.7 \%$ in macrostructural parameters (width, thickness, linear density) and negative changes of $2.1-8.8 \%$ in tensile characteristics were obtained.
\end{abstract}

Keywords: Additives, color difference, mechanical properties, polymeric materials, structure

\section{Introduction}

Different components of additives, polymeric blends and covers as well as various multifunctional compounds and active agents play a vital role in modification of special textiles functionality ${ }^{1-5}$. The polyolefins, namely polypropylene (PP) or polyethylene (PE) are main polymers for tapes production. The polymeric tapes are widely applied in manufacture of textile packages of great capacities for storage of such products as building materials, fertilizers and other dry substances. Modern tendencies of recent developments of tapes manufacture are connected with a use of the new modifications of components, i.e. blends of polyolefins and olefinic monomers ${ }^{1,6,7}$ as well as with the supplementary applications of various types of additives ${ }^{8-19}$ for improving whiteness, antistatic properties, soiling resistance and great number of other qualities. Multifunctional additives can improve homogeneity and mixing of all the components, but their positive/negative effects on basic properties of tapes are almost unknown. The additives can be converted into different solid forms, either master batch pellets or powders. Nano additives of high functionality are also used ${ }^{20-25}$. For enhancement of functional properties of polyolefin materials, the inorganic fillers as calcium carbonate, talc, silica and others are important materials $\mathrm{s}^{8,16,26,27}$. For instance, calcium carbonate provides opacity and surface gloss of polymeric products, but, for complex compositions of tapes, these effects were not studied. It was found in previous work ${ }^{27}$ that the changes in linear densities and tenacities of the tapes can take place after applications of individual amounts of additives and selected melt pump speeds during manufacture. Unfortunately, the composition-property relations, for instance, their types are undisclosed as yet.

* e-mail: donatas.petrulis@ktu.lt
Moreover, for present-day textile materials, several additives as the constituent elements are often used. Therefore, more complex combinations of different additives, when they are used together with polyolefins are needful to be checked. In the current study, the samples of tapes composed of PP component and three types of additives applied together are examined. The aim of the study was to show the effects of variable amounts of special additive for maintenance of whiteness used instead of PP component in the tapes.

\section{Experimental}

The performance of variable amounts of additive Granic 422 (Constab Co., Germany) instead of PP component (Unipetrol Co., Czech Republic) on properties of tapes was evaluated. As can be seen from Table 1, when portion of the additive increases from 3.00 to $7.00 \mathrm{wt} \%$, the portion of $\mathrm{PP}$ component respectively decreases from 92.25 to $88.25 \mathrm{wt} \%$. Additive Granic 422 was applied to impact whiteness to the material. A master batch of calcium carbonate particles was used. The content of calcium carbonate was $80 \mathrm{wt} \%$ and that of linear low-density polyethylene (LLDPE) was $20 \mathrm{wt} \%$. In the current study, LLDPE is a copolymer of ethylene and 1-octene.

The fixed amounts of other two additives, i.e. Polycom JB 7100 (Omega Plasto Compounds Co., India) and UV 01017 PP (Constab Co., Germany) were selected in accordance with experience of preliminary experimentation (Table 1). Additive Polycom JB 7100 was used as modifier, processing aid and bonding agent. In this additive, the portion of inorganic coupling agents and inorganic additives was $75.50 \mathrm{wt} \%$, and the portion of the polyolefins was $24.50 \mathrm{wt} \%$. Additive UV 01017PP was used as a protector of photochemical oxidation.

The melt flow index (MFI) value of additive Granic 422 was $1.2 \mathrm{~g} / 10 \mathrm{~min}$. For additive Polycom JB 7100, the MFI 
Table 1: Composition of tapes (wt $\%)$.

\begin{tabular}{lccccc}
\hline Component & & \multicolumn{3}{c}{ Amount, wt $\%$} \\
sample C & sample D & sample E \\
\hline Additive Granic 422 & 3.00 & sample B & 5.00 & 6.00 & 7.00 \\
Additive Polycom JB 7100 & & & 3.00 for all samples & & \\
Additive UV 01017 PP & & & 1.75 for all samples & & \\
Polypropylene & 92.25 & 91.25 & 90.25 & 89.25 & 88.25 \\
\hline
\end{tabular}

parameter was at a level of $3.8 \mathrm{~g} / 10 \mathrm{~min}$. The MFI value of the PP component was $3.1 \mathrm{~g} / 10 \mathrm{~min}$.

Samples of tapes were produced in single screw extruder E10 (Barmag Saurer Co., Germany). The samples had to go undergo processes of molding of components, extrusion of a film, thermo-acting and cutting into tapes and then their drawing into tapes having about $2.5 \mathrm{~mm}$ width conventional for manufacture of woven packing materials. Betacontrol systems were applied for monitoring of the thickness of a film in its width. In order to have identical conditions for manufacture of samples, all process parameters were used at fixed level. For instance, melt pump speed value was $44.0 \mathrm{~min}^{-1}$. Take-off speed was set at a level of $53.3 \mathrm{~m} / \mathrm{min}$, and take-up speed was 340.0 $\mathrm{m} / \mathrm{min}$. Thus the total draft ratio of the fully drawn products was fixed at a level of 6.380. A distance between the slit dye of extruding device and the cooling unit of $50 \mathrm{~mm}$ was used everywhere. The temperatures in the extruder zones were set at $212-235^{\circ} \mathrm{C}$. At die zone temperature was fixed at a level of $235^{\circ} \mathrm{C}$. The samples were solidified by water at $35^{\circ} \mathrm{C}$. The temperatures at heating oven and annealing stand were $173^{\circ} \mathrm{C}$ and $120^{\circ} \mathrm{C}$, respectively.

The surfaces of tapes and the samples of components were examined using a FEI Quanta ${ }^{\mathrm{TM}} 200$ FEG model (FEI Co., The Netherlands) scanning electron microscope (SEM). Energydispersive X-ray (EDX) spectroscopy was used as a tool of the chemical characterization of materials. Spectrafotometer Spectraflash SF450X (Datacolor Co., USA) with software Datacolor Tools v3.0 was applied to measure color difference $\left(\Delta E_{\mathrm{cmc}}\right)$ according to the standard ${ }^{28}$. The control sample $\mathrm{A}$ was taken as the standard, and the other tapes, i.e. B, C, D and $\mathrm{E}$ were taken as the samples when calculating the color difference. The values of width and thickness of the tapes were measured using special installation. To monitor the tape width, a zoom microscope SM 2800 Achro 0,5x (Nikon Co., Japan) and digital camera Nikon Coolpix 4500 (Nikon Co., Japan) were applied. Software METRIC 7.0 was used to measure the width values. Thickness of tapes was determined by means of thickness gauge (Hans Schmidt \& Co., Germany). To compute the linear densities of the tapes, the samples of fixed length (10 $\mathrm{m})$ were weighed in an EW 150-3M electronic balance (Kern \& Sohn Co., Germany). The tensile properties of all samples were measured on the tensile testing machine H5KT (Tinius Olsen Ltd., United Kingdom) according to requirements of the standard ${ }^{29}$. The specimen length was set to $500 \mathrm{~mm}$, and the speed of the moving clamp was of $500 \mathrm{~mm} / \mathrm{min}$. To avoid the slippage of specimens, the special grips were applied. A pretension $0.5 \mathrm{cN} /$ tex was applied. The breaking forces and elongations at break were obtained from the stress and strain graphs at the breaking point. The values of work of break were determined as the equivalents to the area under force extension curve. Other indices, i.e. breaking tenacity and specific work of break were computed applying values of breaking force, work of break and linear density of the tapes. The values of initial modulus of each specimen were measured at $1.0 \%$ strain, and after that were computed for a level of $100.0 \%$ extension. All measurements were performed with 20 replicates for each sample type at atmospheric conditions as specified in the standard ${ }^{30}$.

The effects of the additive on properties of tapes as well as the statistical values of measurements were determined using Microsoft Excel Data analysis Tool Pak. Confidence level of 0.95 was applied. The values of determination coefficients $\left(R^{2}\right)$ were computed, and after that the empirical equations showing relations between variable portion of additive Granic 422 and properties of tapes were suggested. For this purpose, the well-known least squares method was applied. Finally, the quantitative changes in the basic properties were obtained using the relations of the current study.

\section{Results and Discussions}

In the beginning, additive Granic 422 was examined before its application in manufacture of tapes. Figure 1, where SEM micrograph of the additive is given, indicates that the particles of calcium carbonate have rather smooth surfaces and sharp edges. Minimum dimensions of typical particles of calcium carbonate were about 0.71-1.00 $\mu \mathrm{m}$, and the maximum dimensions were in a range of 4.00-4.50 $\mu \mathrm{m}$. These results are in a line with reference ${ }^{31}$, where it was noted that this additive contains calcium carbonate particles of $1.60 \mu \mathrm{m}$ mean size. In our opinion, the particles can affect continuity of tapes structure. Finally, the dimensions of the particles can be connected with the phenomena of interfacial interaction and load transfer in the tapes.

Using EDX test it was found that the calcium $(\mathrm{Ca})$ was also observed as dominant element of inorganic materials in the tapes. The surfaces of the tapes were examined. As shown in Figure 2, where the test results are given in a qualitative form, the agglomerations of Ca element are very different for samples of tapes containing different amounts of additive Granic 422. Figure 2.b of sample E demonstrates that after application of maximum portion of the additive, the spread of Ca element through the surface of a tape becomes greater if compared with that for initial variant A shown in Figure 2.a. The surfaces of the tapes A and E were also different, i.e. the great indications of the additives were observed for sample E shown in Figure 3.b, but these were less noticeable for sample A given in Figure 3.a.

The results of color difference $\Delta E_{\mathrm{cmc}}$ for tapes show (Figure 4) that additive Granic 422 can effectively improve whiteness of the tapes. The experimental values of $\Delta E_{\mathrm{cmc}}$ tend to increase 


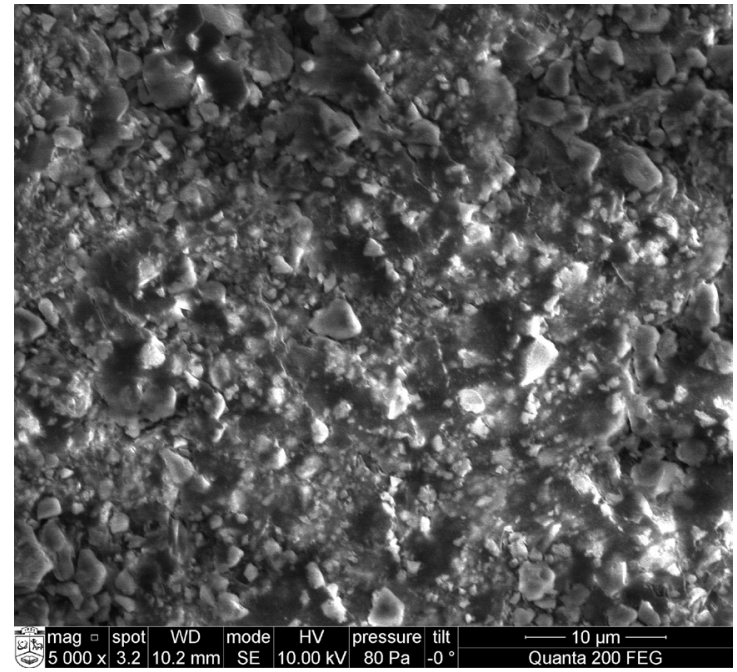

Figure 1: Typical SEM micrograph of additive Granic 422 before application for manufacture of tapes.

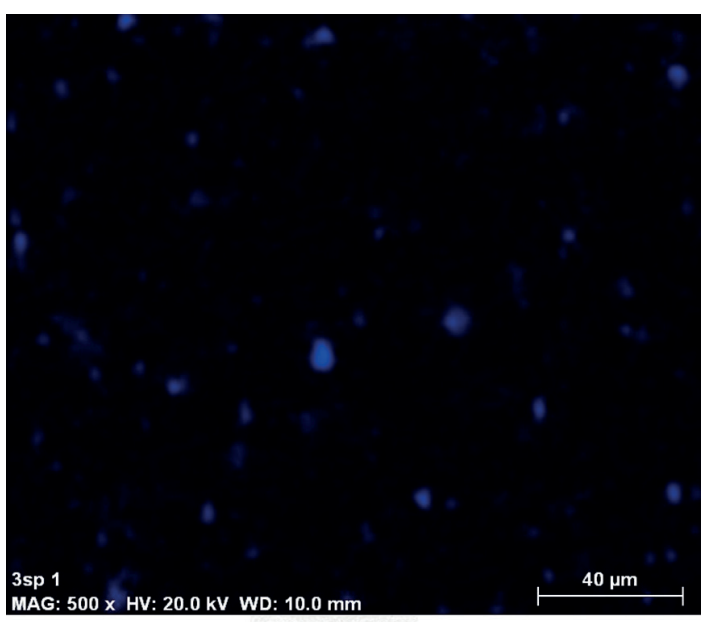

(a)

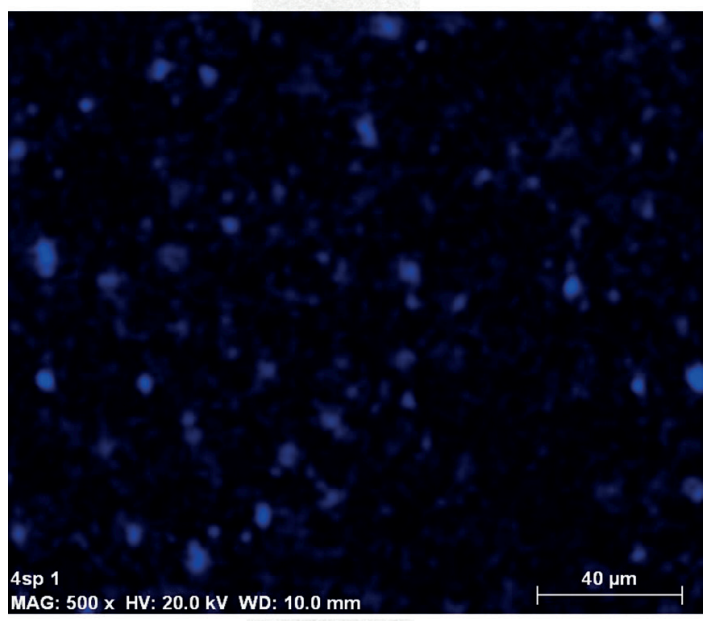

\section{(b)}

Figure 2: Typical EDX test micrographs showing the spread of $\mathrm{Ca}$ element on the surfaces of tapes: $\mathrm{a}$ - sample A, b-sample E.

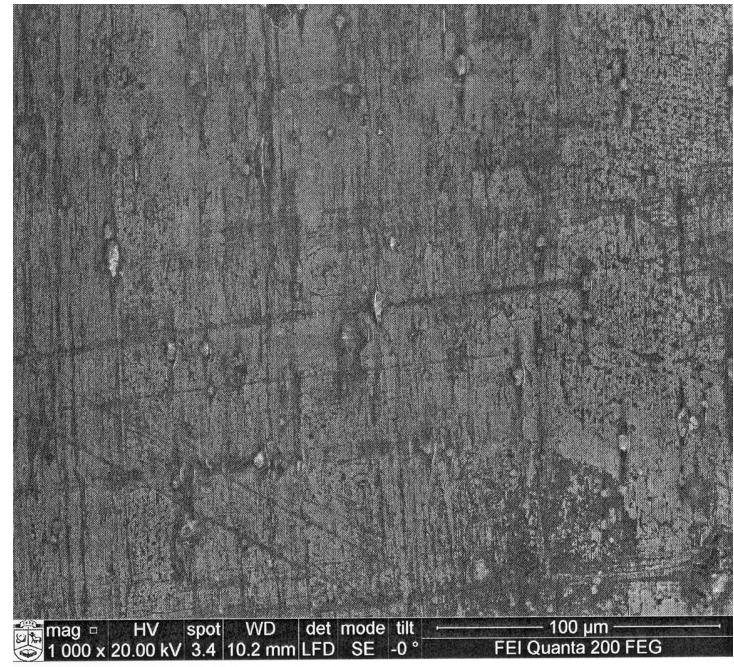

(a)

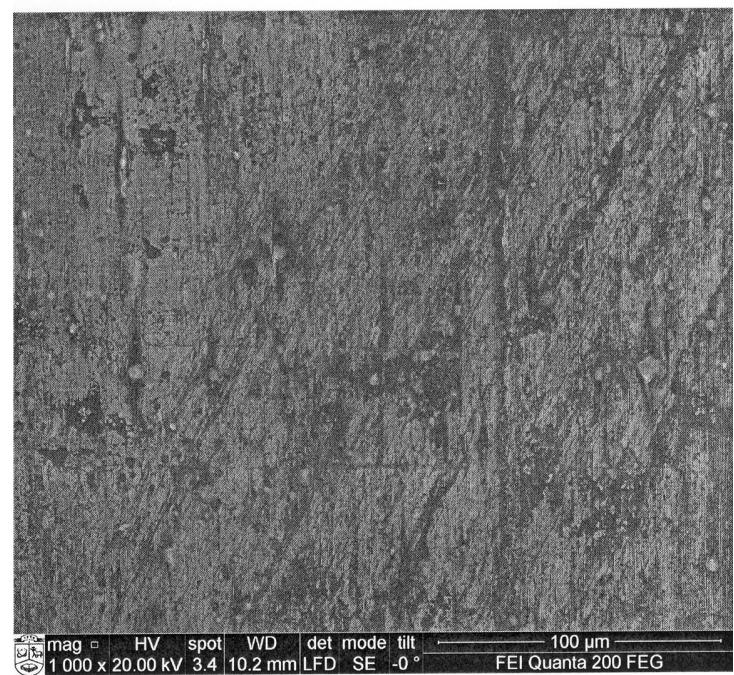

(b)

Figure 3: Typical SEM micrographs of surfaces of tapes: a - sample A, b - sample E.

with the increase in the additive content. The biggest value of $\Delta E_{\mathrm{cmc}}$ was found for sample $\mathrm{E}$ containing maximum portion of additive Granic 422. Meanwhile, other samples (B, C and D) differed from control sample A less. This trend is conditioned by additional applications of calcium carbonate particles which were used as main component in additive Granic 422. It can be seen that especially clear positive changes in $\Delta E_{\mathrm{cmc}}$ were detected for amount up to $5.00 \mathrm{wt} \%$, but further increments of the additive portion have reduced positive effect. To show this nonlinear effect, the logarithmic composition-property relation was suggested, and the value of $R^{2}=0.8798$ was obtained.

The results of the tapes width, thickness and linear density after application of additional amounts of additive Granic 422 are given in Figure 5. From the data obtained it is possible to claim that for all above-mentioned indices of the macro-structure, a tendency of increase can be reported. The enough great values of $R^{2}$, i.e. $0.9552,0.9356$ and 0.9479 were obtained for indices of width, thickness and linear density, respectively. Therefore, 


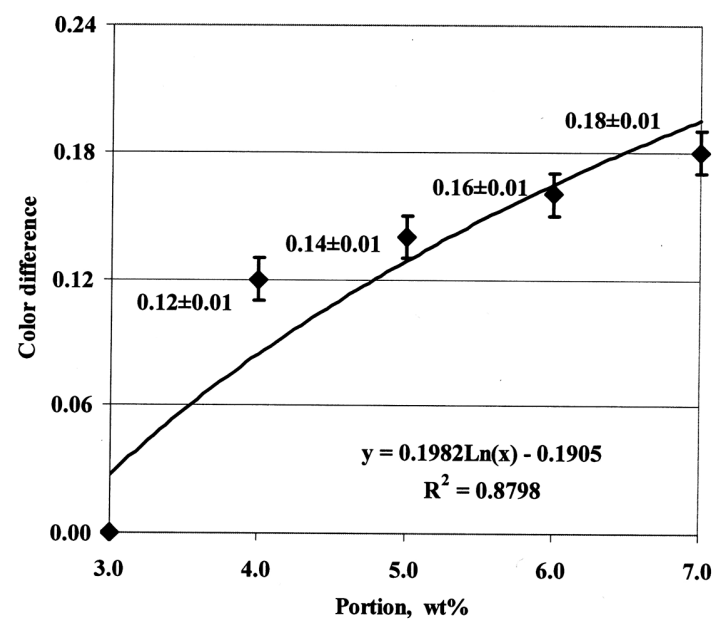

Figure 4: Effect of portion of additive Granic 422 on color difference of tapes.

the strong and positive correlation between the portion of the additive Granic 422 and macro-structure of the tapes can be declared. These tendencies are conditioned by several reasons connected with melt flow changes during extrusion and the other processes of tapes manufacture. For instance, the elastomeric component of the additive, i.e. LLDPE can fill the micro-pores in the tapes better when a maximum portion of the additive is applied. Hence, for such tapes, their cross-sectional dimensions after drawing process are greater. Meanwhile, the samples having open micro-pores can change their cross-sectional dimensions with the greatest intensity. The changes in linear density of tapes are also conditioned by the above-mentioned reasons. Since additive Granic 422 has greater its density ${ }^{31}\left(1.80 \mathrm{Mg} / \mathrm{m}^{3}\right)$ if compared with that of PP component $\left(0.90-0.92 \mathrm{Mg} / \mathrm{m}^{3}\right)$, the linear density of the tapes was also additionally affected by this factor. As it was mentioned earlier, the main component of additive Granic 422 has a great portion of calcium carbonate. Hence, the tapes containing a small amount of the additive and, therefore, a great portion of PP component, have great recoverable elastic deformations developed during manufacture. So, this factor can also explain, why the tapes containing maximum portion of the additive Granic 422 have the greatest widths, thicknesses and linear densities. Other factors, for instance, the smaller MFI value of the variable additive compared with that of PP component, as well as the risk of slippage of tapes after applications of the additive Granic 422, also can be mentioned as possible reasons. If the slippage between tape and the rolls of the extruder increases, the draw ratio of the tape tends to decrease. In our opinion, the accidental slippages for different samples are likely limited because the variations of the tapes in their widths, thicknesses and linear densities fluctuated without clear changes for different samples. Moreover, the variation coefficients of the width, thickness and linear density of tapes were rather similar, i.e. $1.0-1.6 \%, 0.4-0.6 \%, 0.6-0.9 \%$, respectively. Meanwhile, the factor of MFI value of the additive can change the quantity in grams of blended substance of polyolefins and additives during process of extrusion. Since Granic 422 has MFI value less compared with that of PP component, the effect of decrease of cross-sectional parameters of tapes can be expected for samples with the greatest portions of the variable additive. In

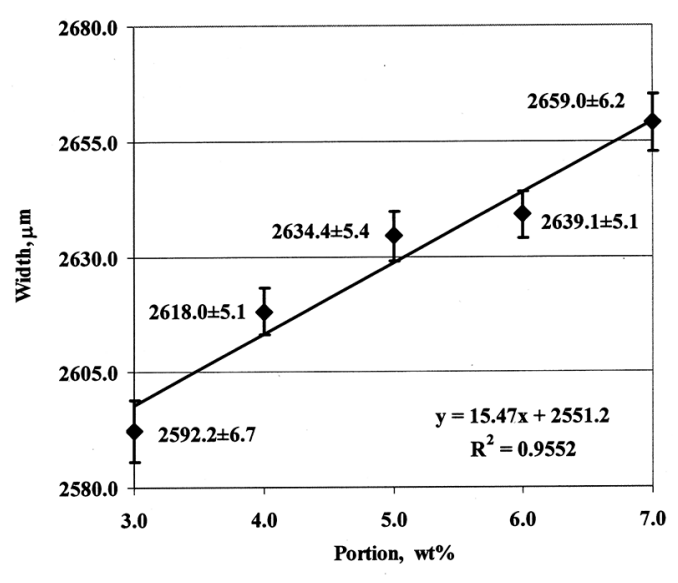

(a)

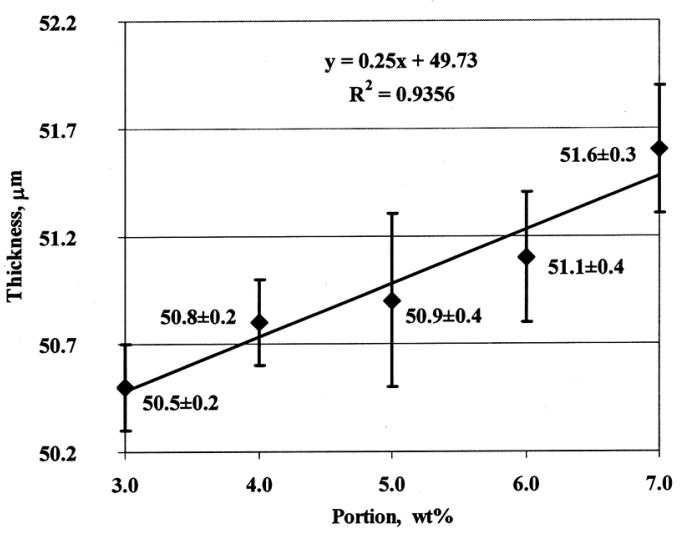

(b)

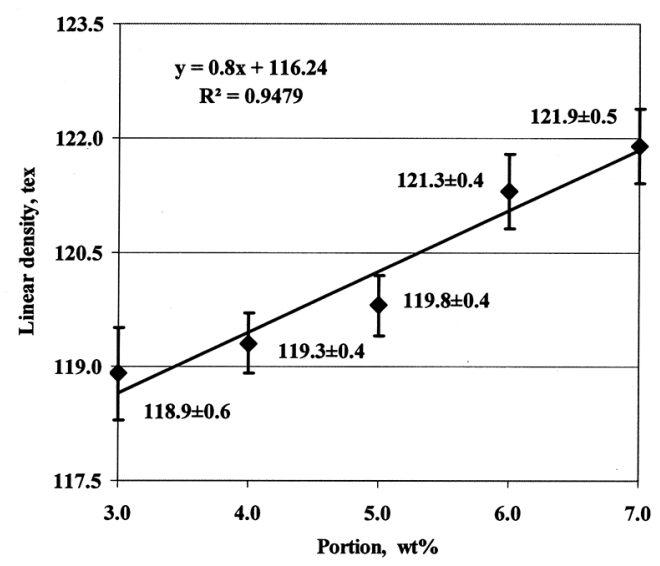

(c)

Figure 5: Effect of portion of additive Granic 422 on macro-structure of tapes: a - width, $\mathrm{b}$-thickness, $\mathrm{c}$ - linear density.

our opinion, this effect was not the strongest, and, therefore, the total tendencies for the changes in macro-structure were mainly conditioned by earlier-mentioned phenomenon of micro-pores.

The effects of Granic 422 portion on tensile indices are shown in Figure 6. The tendencies are as follows. When 


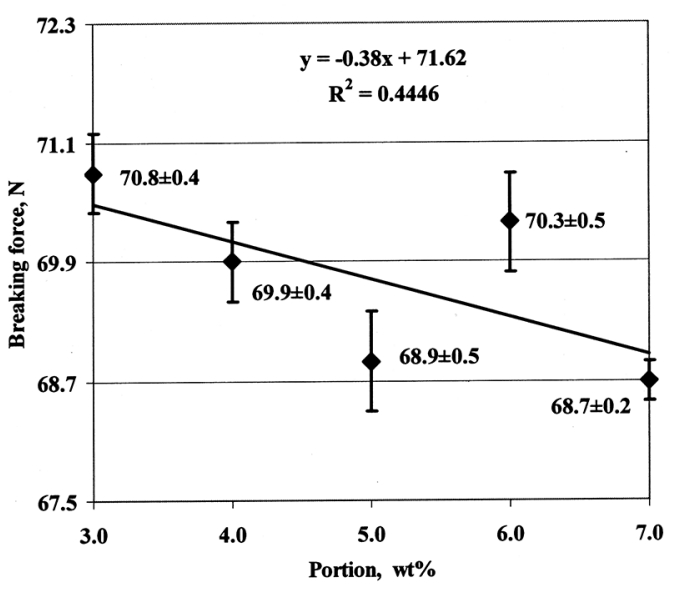

(a)

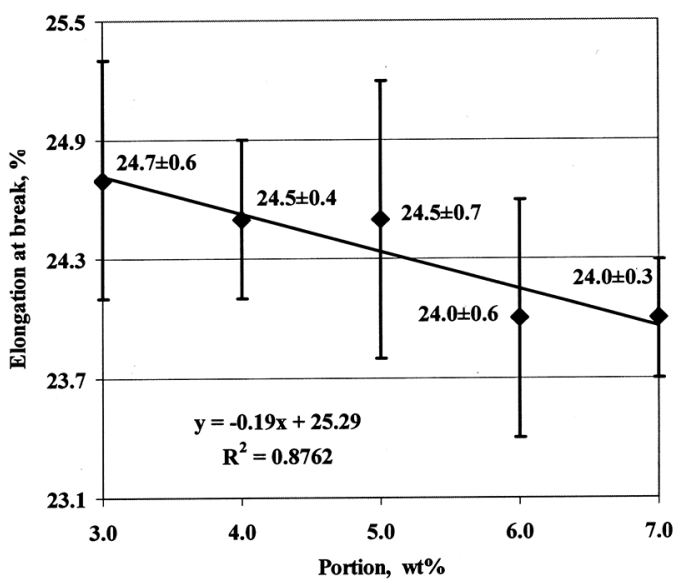

(c)

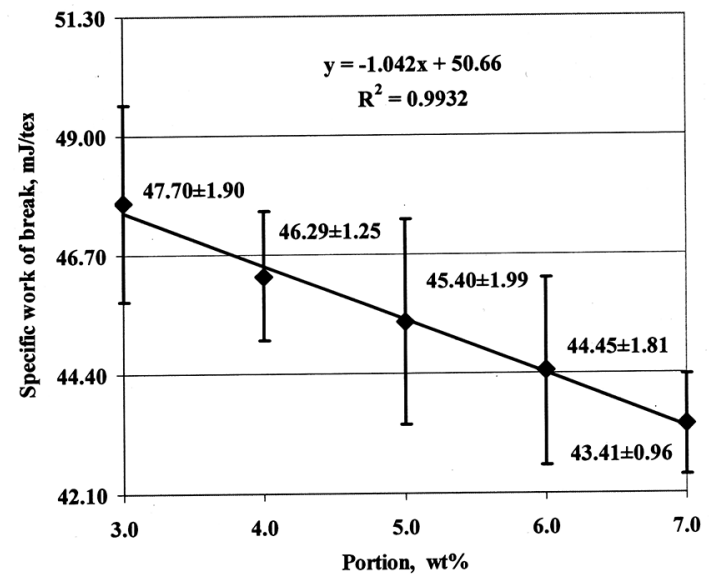

(e)

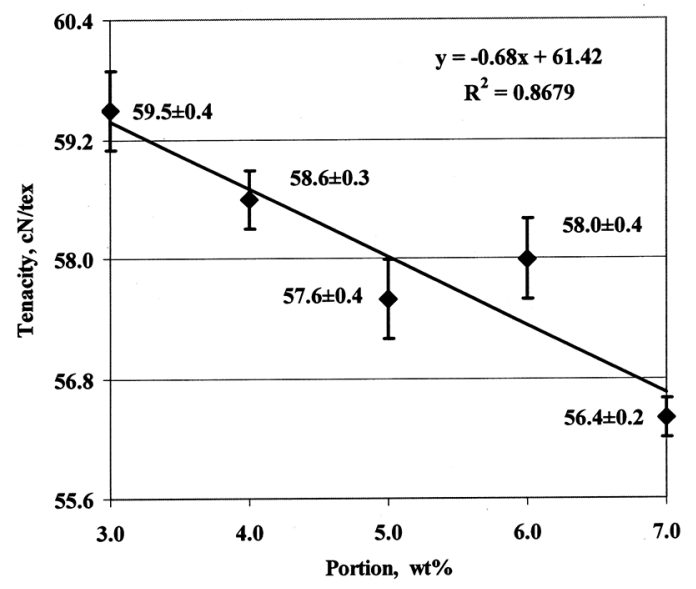

(b)

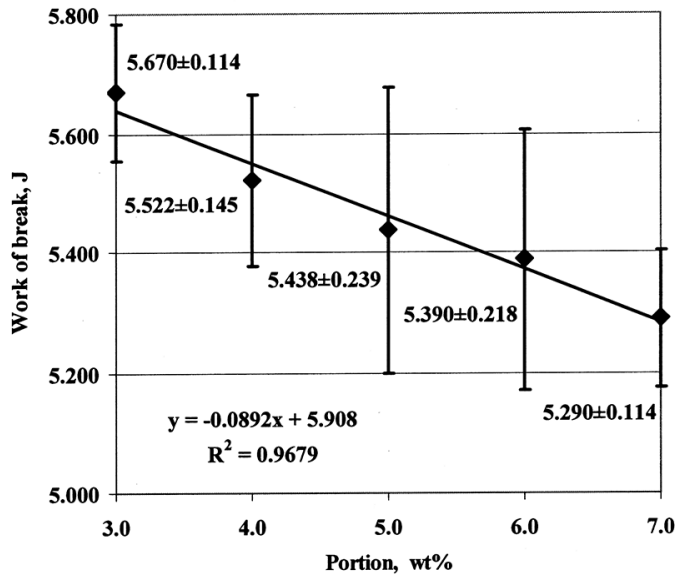

(d)

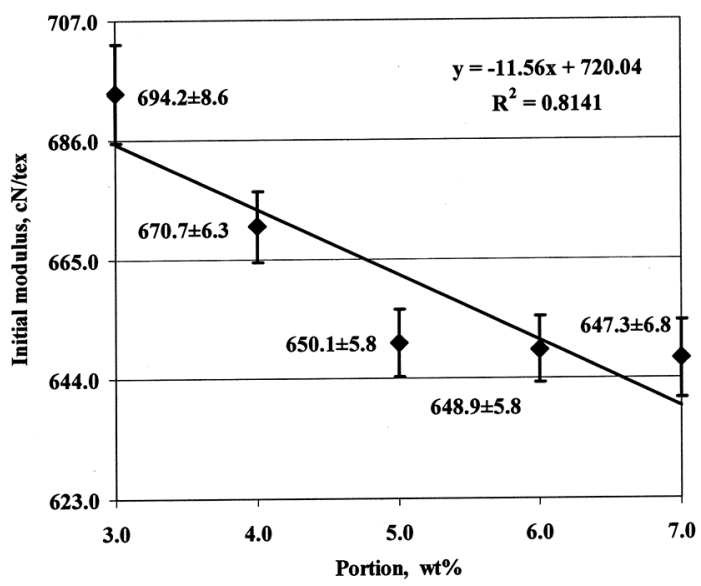

(f)

Figure 6: Effect of portion of additive Granic 422 on tensile properties of tapes: a - breaking force, $\mathrm{b}$ - tenacity, c - elongation at break, $\mathrm{d}$ - work of break, e - specific work of break, $\mathrm{f}$ - initial modulus. 
amount of additive Granic 422 increases and amount of PP component decreases, the tensile indices, namely breaking force, tenacity, elongation at break, work of break, specific work of break and initial modulus of tapes have a tendency to decrease. It is worth to note that these changes can be connected with previously mentioned tendencies of microand macro-structure of tapes. The tensile properties of tapes after applications of the additive are worse, and these tapes, as it was shown earlier, also have greater cross-sectional dimensions and linear densities compared with the initial parameters. Therefore, as a possible reason of such changes can be less ordered molecular orientation. Another negative reason can be connected with the changes in continuity of polymeric tape structure, because inorganic materials as constituent parts of the additive are additionally used. As it was mentioned earlier, especially dimensions of the particles can be fundamental for tensile properties. On the other hand, the tapes with great portions of the additive have filled micro-pores, and therefore, such reason can be mentioned as a positive factor. Figure 6 also shows that the linear relations were obtained for all tensile parameters. For the relations, the values of $R^{2}$ were between 0.4446 and 0.9932 .

In the next stage of a study, the above-mentioned relations were applied to obtain the values of changes in macrostructural and tensile properties. The computed values of indices of sample A were taken as the standard, and after that the calculations for sample E were used to obtain the values of maximum changes. These results are shown in Figure 7. Hence, the positive changes in the widths, thicknesses and linear densities of tapes were obtained. These values varied between +2.0 and $+2.7 \%$. For the tensile indices, the negative changes in a range between -2.1 and $-8.8 \%$ were observed. The smallest losses were obtained for indices of breaking force $(-2.1 \%)$ and elongation at break $(-2.8 \%)$. Other parameters, such as tenacity, work of break, initial modulus and specific work of break had changes between -4.5 and $-8.8 \%$. These findings are consistent with previously mentioned increase in linear density of tapes.

Finally, the current research showed that additive Granic 422 can improve whiteness of tapes. However, the portions of the additive should be carefully added because product tensile properties decrease with its use.

\section{Conclusions}

It was found that the increase in additive Granic 422 additions to the polymeric tapes instead of polypropylene component affects their whiteness, micro-, macro-structure and tensile properties.

The maximum values of tapes color difference, width, thickness and linear density were reached for the additive content of $7.00 \mathrm{wt} \%$. More marked increase of color difference was shown in a range of low portions of the additive. To show such tendency, a logarithmic relation was proposed. Other parameters, i.e. width, thickness and linear density increased linearly at the inspected range of the additive portion. Using the relations, the maximum values of positive changes of $2.0-2.7 \%$ were found in structural properties of tapes. On the other hand, the additive also caused decrease in tensile properties, i.e. breaking force,

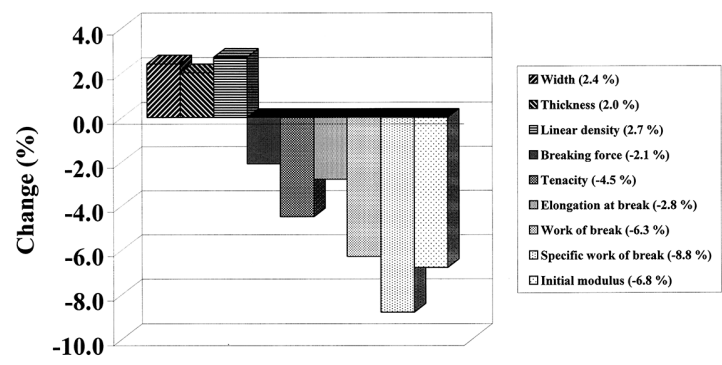

Figure 7: Changes in properties of tapes after application of additive Granic 422 .

tenacity, elongation at break, work of break, specific work of break and initial modulus. The above-mentioned negative changes in properties can be shown using the linear dependences. According to the relations, the tensile properties reduced in about $2.1-8.8 \%$.

Therefore, the structures having the lowest portions of additive Granic 422 for maintenance whiteness produce minimum effects on structural and tensile characteristics of the tapes. When the greatest portions of the additive are applied, the color differences and cross-sectional parameters of the tapes tend to increase, but their tensile parameters have the lowest values.

\section{References}

1. Mather RR. Polyolefin fibres. In: McIntyre JE, ed. Synthetic fibres: nylon, polyester, acrylic, polyolefin. Cambridge: Woodhead Publishing; 2005. p.235-292.

2. Marinković SŠ, Bezbradica D, Škundrić P. Microencapsulation in the textile industry. Chemical Industry \& Chemical Engineering Quarterly. 2006;12(1):58-62. DOI: http://dx.doi.org/10.2298/ CICEQ0601058S

3. Crangle A. Types of polyolefin fibres. In: Ugbolue S, Ed. Polyolefin fibres. Industrial and medical applications. Cambridge: Woodhead Publishing; 2009. p.3-34.

4. Padleckiene I, Petrulis D. Influence of mechanical treatment on air permeability of fabrics with polymeric covers. In: Proceedings of Baltic Polymer Symposium; 2007 Sep 19-21; Druskininkai, Lithuania. p.232-236.

5. George B, Hudson S, McCord MG. Surface features of mineralfilled polypropylene filaments. In: Pastore CM, Kiekens P, eds. Surface characteristics of fibers and textiles. New York: Marcel Dekker Inc.; 2001. p.139-160.

6. Mahajan SJ, Deopura BL, Wang Y. Structure and properties of drawn tapes of high-density polyethylene/ethylene-propylene copolymer blends. II. Journal of Applied Polymer Science. 1996;60(10):1527-1538. DOI: http://dx.doi.org/10.1002/ (SICI)1097-4628(19960606)60:10<1527::AID-APP3>3.0.CO;2-L

7. Alcock B, Cabrera NO, Barkoula NM, Loos J, Peijs T. Interfacial properties of highly oriented coextruded polypropylene tapes for the creation of recyclable all-propylene composites. Journal of Applied Polymer Science. 2007;104(1):118-129. DOI: http:// dx.doi.org/10.1002/app.24588

8. Azizi H, Faghihi J. An investigation on the mechanical and dynamic rheogical properties of single and hybrid filler/polypropylene composites based on talc and calcium carbonate. Polymer Composites. 2009;30(12):1743-1748. DOI: http://dx.doi. org/10.1002/pc.20685 
9. Ujhelyiová A, Marcincin A, Legén J. DSC analysis of polypropylenelow density polyethylene blend fibres. Fibres \& Textiles in Eastern Europe. 2005;13(5):129-132.

10. Ugbolue S. Testing and quality control of polyolefins. In: Ugbolue S, Ed. Polyolefin fibres. Industrial and medical applications. Cambridge: Woodhead Publishing; 2009. p.316-340.

11. Crangle A. Types of polyolefin fibres. In: Ugbolue S, Ed. Polyolefin fibres. Industrial and medical applications. Cambridge: Woodhead Publishing; 2009. p.3-34.

12. Takahashi T, Kimura Y. Improved soiling resistance of polypropylene fibers on the addition of synthetic compounds. Textile Research Journal. 2012;82(8):789-800. DOI: http:// dx.doi.org/10.1177/0040517511433148

13. Shah V. Handbook of plastics testing and failure analysis. New York: John Wiley \& Sons; 2007. 648p.

14. Aubert M, Roth M, Pfaendner R, Wilén CE. Azoalkanes: a novel class of additives for cross-linking and controlled degradation of polyolefins. Macromolecular Materials and Engineering. 2007; 292(6):707-714. DOI: http://dx.doi. org/10.1002/mame.200600498

15. Van de Velde K, Van Wassenhove V, Kiekens P. Optical analyses of pigment particles in color concentrates and polypropylene yarns. Polymer Testing. 2002;21(6):675-689. DOI: http://dx.doi. org/10.1016/S0142-9418(01)00143-X

16. Shamey R. Improving the colouration/dyeability of polyolefin fibres. In: Ugbolue S, Ed. Polyolefin fibres. Industrial and medical applications. Cambridge: Woodhead Publishing; 2009. p.363-397.

17. Mather RR. The structural and chemical properties of polyolefin fibres. In: Ugbolue S, Ed. Polyolefin fibres. Industrial and medical applications. Cambridge: Woodhead Publishing; 2009. p.35-56.

18. Broda J, Gawlowski A, Fabia J, Ślusarczyk C. Supermolecular structure of polypropylene fibres modified by additives. Fibres \& Textiles in Eastern Europe. 2007;15(5-6):30-33. DOI: http:// dx.doi.org/10.1016/j.dyepig.2006.10.004

19. Ahmed SI, Shamey R, Christie RM, Mather RR. Comparison of the performance of selected powder and masterbatch pigments on mechanical properties of mass coloured polypropylene filaments. Coloration Technology. 2006;122(5):282-288. DOI: http://dx.doi.org/10.1111/j.1478-4408.2006.00042.x
20. Marcinčin A, Hricová M, Ujhelyiová A, Brejka O, Michlík P, Dulíková M, et al. Effect of inorganic (nano)fillers on the UV barrier properties, photo and thermal degradation of polypropylene fibres. Fibres \& Textiles in Eastern Europe. 2009;17(6):29-35.

21. Ujhelyiová A, Strecká Z, Bolhová E, Duliková M, Bugaj P. Polypropylene fibres modified polyvinyl alcohol and nanoadditive. Structure and properties. Fibres \& Textiles in Eastern Europe. 2007;15(5-6):37-40.

22. Dulíková M, Strecka Z, Ujhelyiovaá A, Legen J, Bugaj P. Shielding effect of nanoadditives against UV radiation in polypropylene fibres. Fibres \& Textiles in Eastern Europe. 2009;18(5):55-59.

23. Zhu MF, Yang HH. Polypropylene fibres. In: Lewin M, ed. Handbook of fibre chemistry. Cambridge: CRC Press; 2007. p.141-261.

24. Dastjerdi R, Montazer M. A review on the applications of inorganic nano-structured materials in the modification of textiles: Focus on anti-microbial properties. Colloids and Surfaces B: Biointerfaces. 2010;79(1):5-18. DOI: http://dx.doi. org/10.1016/j.colsurfb.2010.03.029

25. Cieślak M, Puchowicz D, Kamińska I. SEM/EDS and Raman micro-spectroscopy examination of titanium-modified polypropylene fibres. Fibres \& Textiles in Eastern Europe. 2014;22(3):47-53.

26. Tolinski M. Additives for polyolefins. Oxford: Elsevier; 2009.

27. Petrulis D, Petravičius, Petrulyte S. Analysis of breaking characteristics of tape yarns made from blends of polyolefins and additives. Fibres \& Textiles in Eastern Europe. 2012;6A(95):63-68.

28. International Organization for Standardization. ISO 105-J03:2009. Textiles -- Tests for colour fastness -- Part J03: Calculation of colour differences. Genéve: ISO; 2009.

29. International Organization for Standardization. ISO 2062:2009. Textiles -- Yarns from packages -- Determination of single-end breaking force and elongation at break using constant rate of extension (CRE) tester. Genéve: ISO; 2005.

30. International Organization for Standardization. ISO 139:2005. Textiles -- Standard atmospheres for conditioning and testing. Genéve: ISO; 2005.

31. Granic. Granic 422 product description. [cited 2016 Jun 16]. Available from: http://media.cylex.pl/ uploadedfiles/10606632_634726735975338644_422_PL.pdf DOI: http://dx.doi.org/10.1353/1lt.2016.0026 